\title{
Etiology and Short Term Outcome of Neonatal Convulsion in NICU at Benghazi Children Hospital
}

\author{
Mohanad Abdulhadi Saleh Lawgali*, Faiaz Ragab Salem Halies, Amina M. Beayou \\ Department of Pediatrics, Faculty of Medicine, University of Benghazi, Benghazi, Libya \\ Email: ^mohanad.lawgali@uob.edu.ly
}

How to cite this paper: Lawgali, M.A.S., Halies, F.R.S. and Beayou, A.M. (2019) Etiology and Short Term Outcome of Neonatal Convulsion in NICU at Benghazi Children Hospital. Neuroscience \& Medicine, 10, 369-384.

https://doi.org/10.4236/nm.2019.104027

Received: August 19, 2019

Accepted: December 1, 2019

Published: December 4, 2019

Copyright () 2019 by author(s) and Scientific Research Publishing Inc. This work is licensed under the Creative Commons Attribution International License (CC BY 4.0).

http://creativecommons.org/licenses/by/4.0/

\begin{abstract}
Background: Neonatal seizures are the most prominent feature of neurological dysfunction during neonatal period, which are abnormal electrical discharges in the central nervous system of neonates, usually manifest as stereotyped muscular activity or autonomic changes, occurring in approximately 1.8 - 3.5/1000 live birth. Objective: The aims of study are to determine prevalence rate, natural history, time of onset, etiological factors, clinical types and the short term outcome of neonatal convulsion. Settings: This study conducted in Neonatal Department at Benghazi Children Hospital-Libya. Patients and Methods: Descriptive cross sectional study, included all neonates who developing clinically identifiable seizures, admitted from $1^{\text {st }}$ of March 2013 to $1^{\text {st }}$ of March 2014. The data collected by using a designed perform including; gender, nationality, residence, place of transfer, gestational age, time of onset, mode of delivery, and history of maternal diseases, family history of neonatal seizures in previous siblings or death, jaundice and exchange transfusion were taken. Details examination include dysmorphic features, weight, head circumference were recorded. Types of seizures were diagnosed by clinical observations, and the etiology of neonatal seizures had been identified from imaging study and from initial relevant investigations which include blood glucose levels, arterial blood gases, serum calcium, electrolytes, phosphate and cerebrospinal fluid examination for evidence of infection. In addition to treatments received, as well as causes of deaths. Results: A total of 2842 neonates were admitted to NNW, out of which 150 had seizures. 86 (57\%) were male with M:F ratio of 1.3:1. (97\%) were Libyan and (76\%) from Benghazi, (42\%) admitted directly from home. 131 (87\%) were term and $15(10 \%)$ preterm. Most of neonatal seizures (76\%) were seen in the $1^{\text {st }}$ week of life, and during initial 72 hours of life (63\%), with $24 \%$ presented in $1^{\text {st }} 24$ hours of life. Vaginal delivery conducted in 101 (67\%), C/S 49 (33\%).
\end{abstract}


Among babies with birth asphyxia, 76\% delivered vaginally. 43/150 mothers presented with different medical problems, $32 \%$ of them had preeclampsia followed by diabetes in $28 \% .127$ (85\%) babies had normal birth weight and $128(86 \%)$ lie within normal range of head circumference. The most common type of seizure was subtle (48\%) followed by clonic (36\%). Cranial ultrasound performed to 110 (73\%), among them, 16 babies MRI or CT scan were done. The most common cause of seizure was birth asphyxia (30\%) followed by infection (16\%), hypocalcemia (14\%). Phenobarbitone was the most common drug used in treatment (60\%), followed by phenytoin (40\%) and resistant cases for treatment received pyridoxine (2\%). 77 (52\%) improved and discharged home without treatment. Mortality rate was $15 \%$; among them $44 \%$ from IEM, followed by birth asphyxia $22 \%$. There is strong association between main causes and the outcome with $\mathrm{p}=0.005$. Conclusion: The majority of neonates in our study were full term and male. The most common etiology of seizures is birth asphyxia. Hypocalcemia is the most common biochemical abnormality. Subtle represents the commonest type of seizure. Phenobarbitone is still the most commonly prescribed anticonvulsant. Inborn error of metabolism carries a higher mortality rate. Statically analysis showed there is significant association between main causes of neonatal convulsions and the outcome with $\mathrm{p}=0.005$.

\section{Keywords}

Neonatal Convulsions, Types, Etiology, Intensive Care, Benghazi, Libya

\section{Introduction}

A seizure or convulsion is a paroxysmal, time-limited change in motor activity and/or behavior that results from abnormal electrical activity in the brain.

Neonatal seizures by definition occur within the first 4 weeks of life in a full-term infant and up to 44 weeks from conception for premature infants (4 weeks after term) and are most frequent during the first 10 days of life [1].

Seizures are more common in the neonatal period than in any other stage and affect approximately $1 \%$ of all neonates, with greater frequency in premature or low birth weight babies as compared to term babies. In the neonatal intensive care units, the incidence goes as high as $10 \%$ to $25 \%$ out of which about $15 \%$ will die and $35 \%$ to $40 \%$ will have major neurological squeal [2].

Recognition and classification of neonatal seizures remain problematic, particularly when clinicians rely only on clinical criteria. The clinical manifestations of seizures in infants differ from those seen in older children and adults. The problem is in electro-clinical dissociation, where there is no temporal correspondence between electrical paroxysms and repetitive stereotyped motor phenomena. There is at present very little information on which clinicians can base a rational decision about treatment which is often ineffective and does not alter neuro developmental outcome. 
Seizures in a newborn are one of the few neonatal neurological emergencies where prompt diagnosis, investigation and treatment are vital as delayed recognition of a treatable cause can have a significant impact on the child's subsequent neurological outcome.

Seizures represent the brain's final common response to insult. The initial injury may be brief, but membrane damage releases excitotoxic substances such as glutamate which triggers further epileptic activity. Magnetic resonance imaging of the brain has shown markedly reduced myelination in children who had suffered from neonatal convulsions [3].

The newborn brain is particularly vulnerable to seizures which are associated with poor neuro developmental outcome. This vulnerability is thought to be due to a combination of enhanced excitability, and low levels of the inhibitory neurotransmitter gamma aminobutyric acid (GABA). That's lead to adverse effect on neurodevelopment and may predispose to cognitive, behavioral or epileptic complication later in life [4] [5].

This study was conducted in neonatal department at Benghazi Children Hospital; it is a referral hospital for all eastern parts of Libya. The department capacity is around 40 incubators, and it is staffed by a highly skilled team from both doctors and nurses. Therefore, the aims of this study were to determine the prevalence rate, the natural history, time of onset, etiological factors, clinical types and to evaluate the short term outcome of neonatal convulsions.

\section{Patients and Methods}

Study design and sitting: This descriptive cross sectional study was conducted in Neonatal Department at Benghazi Children Hospital; the study period was from $1^{\text {st }}$ of March 2013 to $1^{\text {st }}$ of March 2014.

Study population: The study population consisted of 150 neonates admitted to NICU either through neonatal OPD directly from home or referred from other hospitals. During study period, all neonates of either gender developing clinically identifiable seizures before 28 days of life were enrolled in the study (these babies were either admitted with convulsions or developed them after they were hospitalized).

The data: Data was collected by using a designed perform direct from mothers at admission by author himself as well as by reviewing the medical records of the babies which filled by resident doctors in the unit. A detailed history including; gender, nationality, residence, place of transfer either from private or governmental hospital, gestational age, age at onset, mode of delivery (spontaneous vaginal, instrumental, C-section), obstetrical and antenatal history of maternal diseases as gestational diabetes, pregnancy induced hypertension, family history of neonatal seizures in previous siblings or death, as well as jaundice and exchange transfusion were taken.

Details of examination include dysmorphic features, weight, head circumference were recorded. The etiology of neonatal seizures had been identified either 
from imaging study as ultrasound MRI and CT scan results as well as from initial relevant investigations which include blood glucose levels, arterial blood gases, serum calcium, serum electrolytes, serum phosphate and cerebrospinal fluid examination for evidence of infection. In addition to treatments received, as well as causes of deaths.

Diagnostic criteria: Seizure type was diagnosed by clinical observations made by the author or resident doctors, and the etiology was based on laboratory findings, and/or imaging studies of the brain (ultrasonography, CT scan, or MRI). The criteria for diagnosing various biochemical disorders were as follows: hypocalcemia $\left(\mathrm{Ca}^{++}<7.0 \mathrm{mg} / \mathrm{dl}\right)$, hypomagnesemia $\left(\mathrm{Mg}^{++}<1.5 \mathrm{mg} / \mathrm{dl}\right)$, hyponatremia $\left(\mathrm{Na}^{+}<130 \mathrm{mEq} / \mathrm{L}\right)$, hypernatremia $\left(\mathrm{Na}^{+}>150 \mathrm{mEq} / \mathrm{L}\right)$. Hypoglycemia was diagnosed if blood glucose levels were less than $45 \mathrm{mg} / \mathrm{dl}$ in term infants, and less than $40 \mathrm{mg} / \mathrm{dl}$ in preterm infants. CSF examination was considered abnormal when there were elevated CSF leukocytes, low CSF sugar, elevated CSF protein and/or positive culture.

The main causes of convulsion were written as recorded in the patients' file under the title of diagnosis.

Exclusion criteria: All babies meeting the inclusion criteria were included in the study; exclusion criteria included those with no clear clinical signs of convulsions. Jitteriness or sleep-related muscular activities and other non-seizures movements were differentiated from seizures and excluded.

Data and statistical analysis: The data entry, statistical analysis and calculations were performed with the use of statistical package for social sciences software for windows (SSPS version 18.0).

The data interpreted in tables and figures, the numerical data were shown as percent, minimum and maximum, median, mean \pm SD.

Appropriate statistical test of significance like chi-sq test was used as necessary to find the significance of observed difference between the studied variables, and $p$ value $<0.05$ was taken as level of significance.

Limitations: There were limitations in some diagnostic investigations in the hospital like investigations for IEM as well as EEG services.

\section{Results}

Among the 2842 neonates admitted to neonatal care unit during the study period with different medical problems, 150 (5.2\%) neonates (term and preterm) developed clinically identifiable seizures and were found eligible for the study.

\subsection{Demographic Characteristics}

\subsubsection{Gender}

- Male gender dominated the admissions with $86 / 150$ babies (57\%) giving male to female ratio 1.3:1. As shown in Figure 1.

\subsubsection{Nationality}

- Nearly all babies, 146 (97\%) were Libyan. 
- Only 4 (3\%) babies were non Libyan (Syrian). See Figure 2.

\subsubsection{Residence and Place of Transfer}

- The vast majority of the babies 114 (76\%) were from Benghazi; forty eight babies (42\%) admitted directly from their homes through hospital neonatal OPD. Other 66 babies transferred from other hospitals including 45 babies from governmental hospitals and 21 babies from private hospitals.

- All babies referred from outside Benghazi were delivered in governmental hospitals and were as follow (10 from Al Bayda, 7 from Ajdabiya, 6 from $\mathrm{Al}$ Marj, 5 from Darnah, 2 from Sabha, 2 from Tobruk, 2 from Al Abyar, 1 from Kufra, 1 from Sirt).

Figure 3 and Table 1 below illustrate the residence and place of transfer of all babies.

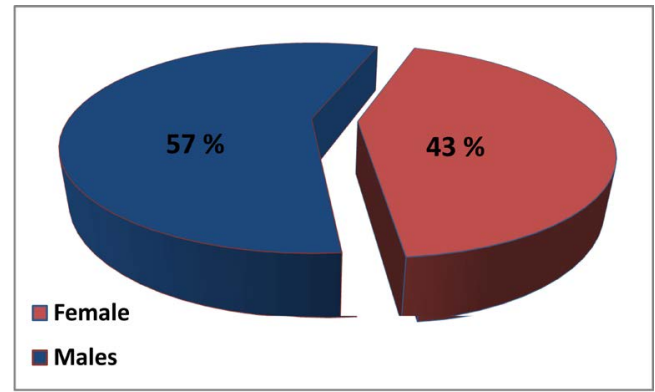

Figure 1. Distribution of babies according to their gender $(n=150)$.

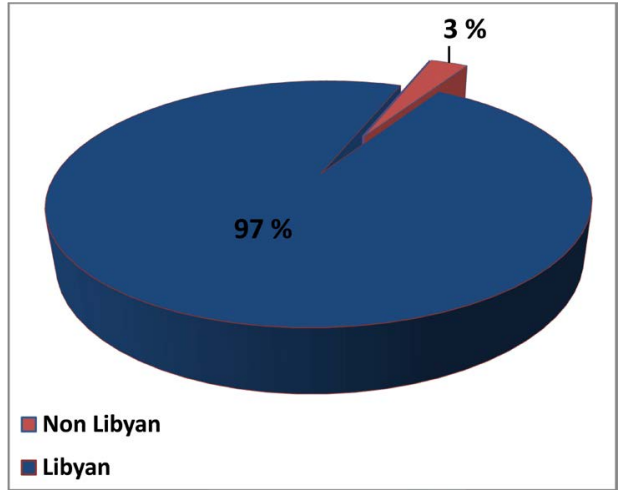

Figure 2. Distribution of babies according to their nationality $(\mathrm{n}=150)$.

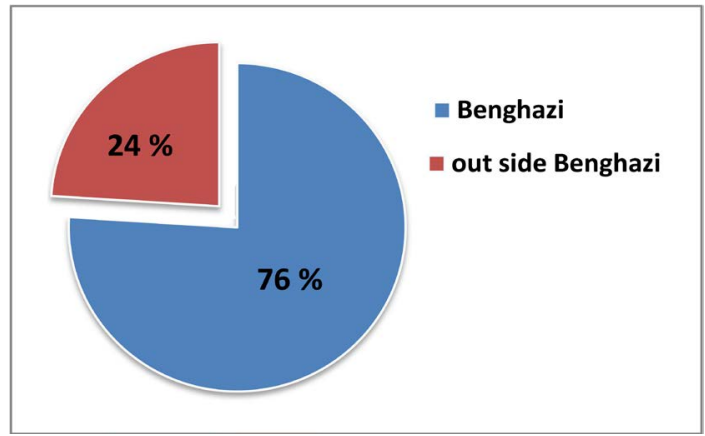

Figure 3. Distribution of babies according to their residence $(n=150)$. 


\subsubsection{Gestational Age}

According to WHO, preterm is defined as baby born alive before 37 weeks of pregnancy are completed. Term baby, between the complete 37 and 42 weeks while post term baby, after 42 weeks.

- In our study group; the vast majority of babies 131 (87\%) were term;

- While 15 (10\%) babies were born prematurely;

- Only 4 (3\%) babies were post term, as shown in Table 2.

\subsubsection{Age at Presentation}

- Their age at presentation ranged from birth to 28 days with median 6 days and mean of $(8.2 \pm 7.1 \mathrm{SD})$.

- We classified the neonatal seizures by age of onset into early onset $<3$ days and late onset after 3 days of age.

- Most of the neonatal seizures occurred in the $1^{\text {st }}$ week of life 114 (76\%) babies.

- During initial 72 hours of life 94 (63\%) babies developed seizures.

- $1^{\text {st }} 24$ hours or at the time of delivery, seizures were seen in $36(24 \%)$ babies, while in the second and third days 58 (39\%) babies and $>3-7$ days, $20(13 \%)$ babies. See Table 3.

Table 1. Distribution of babies according to place of transfer $(n=150)$.

\begin{tabular}{ccccc}
\hline \multirow{2}{*}{ Place of Transfer } & \multicolumn{2}{c}{ Benghazi } & \multicolumn{2}{c}{ Outside Benghazi } \\
\cline { 2 - 5 } & No. & $\%$ & No. & $\%$ \\
\hline Governmental Hospitals & 45 & $40 \%$ & 36 & $100 \%$ \\
Private Hospitals & 21 & $18 \%$ & 0 & $0 \%$ \\
Direct from Home & 48 & $42 \%$ & 0 & $0 \%$ \\
Total & 114 & $100 \%$ & 36 & $100 \%$ \\
\hline
\end{tabular}

Table 2. Distribution of babies according to gestational age $(n=150)$.

\begin{tabular}{ccc}
\hline Gestational age & No. & $\%$ \\
\hline Term & 131 & $87 \%$ \\
Preterm & 15 & $10 \%$ \\
Post term & 4 & $3 \%$ \\
Total & 150 & $100 \%$ \\
\hline
\end{tabular}

Table 3. Distribution of babies according to time of onset $(n=150)$.

\begin{tabular}{|c|c|c|c|}
\hline Onset type & Time of onset & No. & $\%$ \\
\hline \multirow{2}{*}{ Early onset } & $1^{\text {st }} 24$ hours & 36 & $24 \%$ \\
\hline & $2-3$ days & 58 & $39 \%$ \\
\hline \multirow{2}{*}{ Late onset } & $>3$ - 7 days & 20 & $13 \%$ \\
\hline & $>7$ days & 36 & $24 \%$ \\
\hline \multicolumn{2}{|c|}{ Total } & 150 & $100 \%$ \\
\hline
\end{tabular}




\subsubsection{Mode of Delivery}

- Vaginal deliveries were conducted in $101(67 \%)$ mothers, among them 10 (6\%) were assisted deliveries; 8 by vacuum and 2 by forceps.

- Cesarean sections were done in 49 (33\%) mothers, 39 as elective and 10 emergency.

- Among 45 babies with birth asphyxia, nearly three quarters (76\%) delivered vaginally and (24\%) by C/S.

Table 4 and Figure 4 below illustrate mode of delivery and its correlation to birth asphyxia.

\subsection{Maternal Diseases}

- Among 43 mothers with different medical problems, 14 (32\%) mothers had preeclampsia. Followed by diabetes in 12 (28\%) mothers including; diabetes mellitus type I and II as well as gestational diabetes, 2 babies of these mothers had hypoglycemia while hypocalcemia found in third one.

- Hypocalcemia 6 (14\%) mothers, as well as 2 of their babies.

- Three (7\%) mothers had epilepsy; the causes of convulsions in their babies were one with hypocalcemia, the second one with hyponatremia and the third one with ICH. As shown in Table 5.

\subsection{Birth Weight}

According to baby growth chart published by WHO; Normal birth weight ranged from 2.5 - $4.5 \mathrm{~kg}$, and low birth weight (LBW) between $1.5-<2.5 \mathrm{~kg}$.

- Out of 150 babies, 127 (85\%) had normal birth weight with; \{36 (24\%) babies 2.5 - $3 \mathrm{~kg}, 57$ (38\%) babies $>3-3.5 \mathrm{~kg}, 34$ (23\%) babies $>3.5-4.5 \mathrm{~kg}$.

- Eighteen babies (12\%) were LBW (<2.5 kg) included; 15 preterm with $6(4 \%)$ of them less than $2 \mathrm{~kg}$.

- Five (3\%) babies were large for gestational age (>4.5 kg). See Table 6.

Table 4. Distribution of babies according to way of delivery $(n=150)$.

\begin{tabular}{|c|c|c|c|c|c|}
\hline \multicolumn{2}{|c|}{ Mode of delivery } & \multicolumn{2}{|c|}{ No. } & \multicolumn{2}{|c|}{$\%$} \\
\hline \multirow{2}{*}{$\mathrm{C} / \mathrm{S}$} & Elective & \multirow{2}{*}{49} & 39 & \multirow{2}{*}{$33 \%$} & $26 \%$ \\
\hline & Emergency & & 10 & & $7 \%$ \\
\hline \multirow{2}{*}{ Vaginal delivery } & Normal & \multirow{2}{*}{101} & 91 & \multirow{2}{*}{$67 \%$} & $61 \%$ \\
\hline & Assisted & & 10 & & $6 \%$ \\
\hline \multicolumn{2}{|c|}{ Total } & \multicolumn{2}{|c|}{150} & \multicolumn{2}{|c|}{$100 \%$} \\
\hline
\end{tabular}

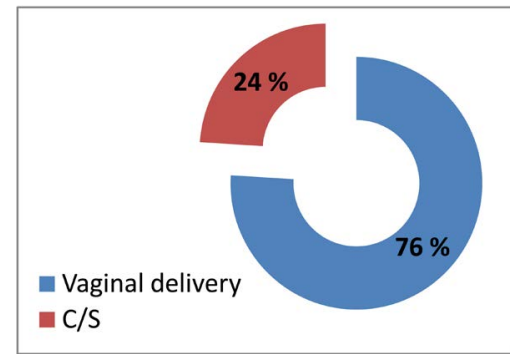

Figure 4. Correlation between birth asphyxia and way of delivery $(n=45)$. 
Table 5. Distribution of babies according to maternal diseases $(n=43)$.

\begin{tabular}{ccc}
\hline Maternal diseases & No. & $\%$ \\
\hline Preeclampsia & 14 & $32 \%$ \\
Diabetes & 12 & $28 \%$ \\
UTI & 8 & $19 \%$ \\
Hypocalcemia & 6 & $14 \%$ \\
Epilepsy & 3 & $7 \%$ \\
Total & 43 & $100 \%$ \\
\hline
\end{tabular}

Table 6. Distribution of babies according to birth weight $(n=150)$.

\begin{tabular}{ccc}
\hline Birth weight/kg & No. & $\%$ \\
\hline $1.5-<2.5$ & 18 & $12 \%$ \\
$2.5-4.5$ & 127 & $85 \%$ \\
$>4.5-5$ & 5 & $3 \%$ \\
Total & 150 & $100 \%$ \\
\hline
\end{tabular}

\subsection{Head Circumference}

According to WHO, normal range of head circumference in term newborn is 35 $\pm 2 \mathrm{~cm}$.

- The vast majority of the babies $128(86 \%)$ lie within normal range.

- Seventeen (11\%) babies, their head circumference were less than $33 \mathrm{~cm}$, among them 15 were preterm babies.

- Five (3\%) babies were above $37 \mathrm{~cm}$. As shown in Table 7.

\subsection{Types of Convulsions}

- Nearly half of the babies 72 (48\%) had subtle convulsion.

- More than one third 54 (36\%) babies had clonic convulsion.

- Tonic in 20 (13\%) babies.

- Only four babies (3\%) had myoclonic convulsion. See Table 8.

\subsection{Imaging Done}

- For the most of babies, $110(73 \%)$ cranial ultrasound was performed, additional imaging CT or MRI was done to $16 / 110$ as guided according to history, physical examination and investigations, which reviled 5 babies with ICH and 20 babies with brain edema. As shown in Table 9.

\subsection{Main Causes of Neonatal Convulsions}

- Frequency of causes of fits was birth asphyxia which considered as a leading cause of convulsions 45 (30\%) babies; Twenty nine of them were an isolated asphyxia and the remaining 16 babies additional problems coexist with birth asphyxia like hypocalcemia 7 babies, electrolyte disturbances 5 and hypoglycemia 4 
Table 7. Distribution of babies according to head circumference $(n=150)$.

\begin{tabular}{ccc}
\hline Head circumference/cm & No. & $\%$ \\
\hline$<33$ & 17 & $11 \%$ \\
$33-37$ & 128 & $86 \%$ \\
$>37$ & 5 & $3 \%$ \\
Total & 150 & $100 \%$ \\
\hline
\end{tabular}

Table 8. Distribution of babies according to type of convulsions $(n=150)$.

\begin{tabular}{ccc}
\hline Type of convulsions & No. & $\%$ \\
\hline Subtle & 72 & $48 \%$ \\
Clonic & 54 & $36 \%$ \\
Tonic & 20 & $13 \%$ \\
Myoclonic & 4 & $3 \%$ \\
Total & 150 & $100 \%$ \\
\hline
\end{tabular}

Table 9. Distribution of babies according to imaging.

\begin{tabular}{cc}
\hline Types of imaging & No. \\
\hline Cranial US & $110 / 150$ \\
CT & $12 / 110$ \\
MRI & $4 / 110$ \\
EEG & 0 \\
\hline
\end{tabular}

babies but the exact contribution of these abnormalities as a cause of seizures is not certain. Another 3 babies had associated aspiration pneumonia.

- Infections, which include sepsis 13 (9\%) babies and meningitis 11 (7\%) babies; among them 3 babies had hypocalcemia, two had electrolyte disturbances and only one with hypoglycemia.

- Biochemical abnormalities; a variety of biochemical abnormalities were demonstrated in 48 babies as a primary cause of seizures including:

- Hypocalcemia is the commonest one with 21 (14\%) babies; among them IDM with TTN, duodenal atresia and operated infantile sacrococcygeal teratoma one baby each, also 2 babies had history of hypocalcemia in their mothers.

- Electrolyte disturbances 12 (9\%) babies; with 7 babies had hypernatremia. 5 babies had hyponatremia, one of them had necrotizing enterocolitis and the other one aspiration pneumonia.

- Hypomagnesemia seen in 3 babies.

- Hypoglycemia in 12 (14\%) babies; among them congenital heart disease and IDM 2 babies each.

- Inborn error of metabolism 15 (10\%) babies; four of them diagnosed as maple syrup urine disease and one as organic acidaemia. The others 10 just diagnosed 
clinically as well as from family history and from course of the disease.

- CNS structural defects 9 (5\%) babies; 6 with hydrocephalus (two edwards syndrome and one robinow syndrome), one with operated encephalocele, one patau syndrome with holoprosencephaly, and other one with operated meningiocele.

- Intracranial hemorrhage (IVH) 5 (3\%) babies, all were preterm.

- Four (3\%) babies had kernicterus; their total serum bilirubin were as follow: $26.2,28.7,37,38.2 \mathrm{mg} / \mathrm{dl}$. one of them had hypocalcemia.

Table 10 and Table 11 below illustrate main causes of convulsion and coexistence biochemical abnormalities with the main causes.

\subsection{Medications}

All babies received one or more types of treatments during their admission:

- Nearly two third $90(60 \%)$ babies received phenobarbitone as $1^{\text {st }}$ line of treatment, followed by Phenytoin 63 (40\%) babies. Dextrose $10 \%$ was given to 42 (28\%) and Calcium gluconate to 15 (10\%) babies, resistant cases for treatment received Pyridoxine (2\%).

- $50 / 150$ (33\%) babies discharged on anticonvulsant treatment; the vast majority of them (88\%) discharged with one drug only. Six (12\%) babies with two drugs; 4 babies with (oral Luminal and calcium gluconate), others 2 with (oral Luminal and Clonazepam).

Table 12 and Table 13 below show the medications used during admissions and after discharge.

\subsection{The outcome}

- Seventy seven (52\%) babies improved and discharged home without treatment in satisfactory condition.

- Fifty (33\%) babies discharged with treatment.

- Twenty three (15\%) babies were died. As shown in Figure 5.

\subsection{The Correlations}

\subsubsection{Correlation between Babies's Gender and the Outcome}

- Half of babies in both gender discharged without treatments.

- Death rate was nearly the same in both gender with $15 \%$ in male and $16 \%$ in female. As shown in Table 14.

- There is no significance association between baby's gender and the outcome with $\mathrm{p}=0.960$.

\subsubsection{Correlation between Babies's Residence and the Outcome}

- According to residence, there is no difference in both group of babies regarding to treatments at discharge or in death rate. See Table 15.

- There is no significance association between baby's residence and the outcome with $\mathrm{p}=0.912$. 


\subsubsection{Correlation between Gestational Age and the Outcome}

- One third of preterm babies were discharged without treatments versus $53 \%$ in term babies.

- In spite of that preterm babies had a higher rate $40 \%$ of treatments needed at discharged as well as higher death rate with $27 \%$ versus $33 \%, 14 \%$ respectively in term babies, there is no significance association between gestational age and the outcome with $\mathrm{p}=0.455$. As shown in Table 16 .

Table 10. Distribution of babies according to main causes of convulsions $(n=150)$.

\begin{tabular}{ccc}
\hline Main causes & No. & $\%$ \\
\hline Birth asphyxia & 45 & $30 \%$ \\
Infection $^{*}$ & 24 & $16 \%$ \\
Biochemical abnormalities & & \\
Hypocalcemia & 21 & $14 \%$ \\
Electrolyte disturbances & 12 & $8 \%$ \\
Hypoglycemia & 12 & $8 \%$ \\
Hypomagnesemia & 3 & $2 \%$ \\
Inborn Error of Metabolism & 15 & $10 \%$ \\
CNS structural defects & 9 & $6 \%$ \\
Intra Cranial Hemorrhage (IVH) & 5 & $3 \%$ \\
Kernicterus & 4 & $3 \%$ \\
Total & 150 & $100 \%$ \\
\hline
\end{tabular}

*Sepsis and meningitis.

Table 11. Biochemical abnormalities and main causes of convulsions.

\begin{tabular}{cccccc}
\hline \multirow{2}{*}{ Main causes } & \multicolumn{3}{c}{ Biochemical abnormalities } \\
\cline { 2 - 5 } & Hyponatremia & Hypernatremia & Hypomagnesemia & Hypocalcemia & Hypoglycemia \\
\hline Birth asphyxia & 2 & 3 & 0 & 7 & 4 \\
Meningitis & 0 & 1 & 0 & 2 & 1 \\
Sepsis & 1 & 0 & 0 & 1 & 0 \\
Hypocalcemia & 0 & 0 & 0 & 21 & 0 \\
Hypornatremia & 5 & 0 & 0 & 0 & 0 \\
Hypernatremia & 0 & 7 & 0 & 0 & 0 \\
Hypoglycemia & 0 & 0 & 0 & 0 & 12 \\
Hypomagnesemia & 0 & 0 & 3 & 0 & 0 \\
IEM & 0 & 0 & 0 & 1 & 0 \\
CNS s.d & 0 & 0 & 0 & 1 & 0 \\
ICH & 0 & 0 & 0 & 0 & 0 \\
Kernicterus & 0 & 0 & 0 & 1 & 0 \\
Total & 8 & 11 & 3 & 34 & 17
\end{tabular}

N.B.: CNS s.d = CNS structural defects, IEM = Inborn Error of Metabolism, $\mathrm{ICH}=$ Intra Cranial Hemorrhage. 
Table 12. Medications received during admission $(n=150)$.

\begin{tabular}{ccc}
\hline Medications & Babies No. & $\%$ \\
\hline Phenobarbitone & 90 & $60 \%$ \\
Phenytoin & 63 & $40 \%$ \\
Dextrose 10\% & 42 & $28 \%$ \\
Calcium gluconate & 15 & $10 \%$ \\
Magnesium sulphate & 10 & $7 \%$ \\
Diazepam & 9 & $6 \%$ \\
Midazolam & 8 & $5 \%$ \\
Clonazepam & 4 & $3 \%$ \\
Pyridoxine & 3 & $2 \%$ \\
\hline
\end{tabular}

Table 13. Distribution of babies according to medications at discharge $(n=50)$.

\begin{tabular}{ccc}
\hline Medications at discharge & No. & $\%$ \\
\hline One drug & 44 & $88 \%$ \\
Two drugs & 6 & $12 \%$ \\
Total & 50 & $100 \%$ \\
\hline
\end{tabular}

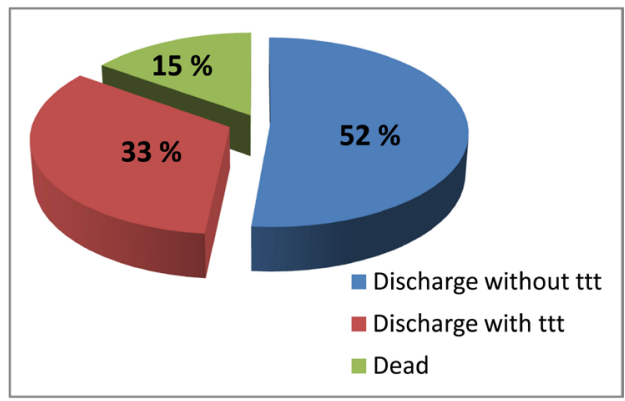

Figure 5. Distribution of babies according to their outcome $(n=150)$.

Table 14. Correlation between babies' gender and the outcome.

\begin{tabular}{|c|c|c|c|c|c|}
\hline \multirow{3}{*}{ Outcome } & \multicolumn{4}{|c|}{ Gender } & \multirow{3}{*}{ Total } \\
\hline & \multicolumn{2}{|c|}{ Male } & \multicolumn{2}{|c|}{ Female } & \\
\hline & No. & $\%$ & No. & $\%$ & \\
\hline Discharge without ttt & 45 & $52 \%$ & 32 & $50 \%$ & 77 \\
\hline Discharge with ttt & 28 & $33 \%$ & 22 & $34 \%$ & 50 \\
\hline Died & 13 & $15 \%$ & 10 & $16 \%$ & 23 \\
\hline Total & 86 & $100 \%$ & 64 & $100 \%$ & 150 \\
\hline
\end{tabular}

Chi-Square Tests: $\chi^{2}=.081, \mathrm{df}=2, \mathrm{p}=0.960$. 
Table 15. Correlation between babies' residence and the outcome.

\begin{tabular}{cccccc}
\hline \multirow{2}{*}{ Outcome } & \multicolumn{4}{c}{ Residence } & \multirow{2}{*}{ Total } \\
\cline { 2 - 4 } & \multicolumn{2}{c}{ Benghazi } & \multicolumn{2}{c}{ Outside Benghazi } & \\
\cline { 2 - 5 } & No. & $\%$ & No. & $\%$ & \\
\cline { 2 - 4 } Discharge without ttt & 58 & $51 \%$ & 19 & $53 \%$ & 77 \\
Discharge with ttt & 39 & $34 \%$ & 11 & $30 \%$ & 50 \\
Died & 17 & $15 \%$ & 6 & $17 \%$ & 23 \\
Total & 114 & $100 \%$ & 36 & $100 \%$ & 150 \\
\hline
\end{tabular}

Chi-Square Tests: $\chi^{2}=0.184, \mathrm{df}=2, \mathrm{p}=0.912$.

Table 16. Correlation between gestational age and the outcome.

\begin{tabular}{cccccccc}
\hline & \multicolumn{5}{c}{ Gestational age } & \\
\cline { 2 - 6 } Outcome & \multicolumn{2}{c}{ Preterm } & \multicolumn{2}{c}{ Term } & \multicolumn{2}{c}{ Post term } & \multirow{2}{*}{ Total } \\
\cline { 2 - 6 } & No. & $\%$ & No. & $\%$ & No. & $\%$ & \\
\hline Discharge without ttt & 5 & $33 \%$ & 69 & $53 \%$ & 3 & $75 \%$ & 77 \\
Discharge with ttt & 6 & $40 \%$ & 43 & $33 \%$ & 1 & $25 \%$ & 50 \\
Died & 4 & $27 \%$ & 19 & $14 \%$ & 0 & $0 \%$ & 23 \\
Total & 15 & $100 \%$ & 131 & $100 \%$ & 4 & $100 \%$ & 150 \\
\hline
\end{tabular}

Chi-Square Tests: $\chi^{2}=3.651, \mathrm{df}=4, \mathrm{p}=0.455$.

\subsubsection{Correlation between Age at Presentation and the Outcome}

- There is no difference in babies who presented early or late with convulsion, where nearly half of babies in both group discharged without treatments as well as death rate was nearly similar in both group. See Table 17.

- There is no significance association between age at presentation and the outcome with $\mathrm{p}=0.999$.

\subsubsection{Correlation between Way of Delivery and the Outcome}

- There is no difference in the outcome between babies who delivered vaginally or by $\mathrm{C} / \mathrm{S}$, where half of them discharged without treatments with nearly equal percentages of death, $16 \%$ and $14 \%$ respectively. As shown in Table 18.

- There is no significance association between way of delivery and the outcome with $\mathrm{p}=0.954$.

\subsubsection{Correlation between Main Causes and the Outcome}

- Prognosis was poor in babies with IEM followed by ICH, CNS structural defects and kernicterus where the death rate was $67 \%, 60 \%, 33 \%$ and $25 \%$ respectively. While babies with birth asphyxia 21/45 (47\%) of them discharged with anticonvulsant therapy as well as 4/15 (27\%) with IEM. See Table 19.

- There is significance association between main causes of neonatal convulsions and the outcome with $\mathrm{p}=0.005$. 
Table 17. Correlation between time of onset and the outcome.

\begin{tabular}{|c|c|c|c|c|c|c|c|c|c|}
\hline \multirow{4}{*}{ Outcome } & \multicolumn{8}{|c|}{ Time of onset } & \multirow{4}{*}{ Total } \\
\hline & \multicolumn{4}{|c|}{ Early } & \multicolumn{4}{|c|}{ Late } & \\
\hline & \multicolumn{2}{|c|}{$1^{\text {st }} 24 \mathrm{~h}$} & \multicolumn{2}{|c|}{2 - 3 days } & \multicolumn{2}{|c|}{$>3-7$ days } & \multicolumn{2}{|c|}{$>7$ days } & \\
\hline & No. & $\%$ & No. & $\%$ & No. & $\%$ & No. & $\%$ & \\
\hline Discharge without ttt & 18 & $50 \%$ & 30 & $52 \%$ & 11 & $55 \%$ & 18 & $50 \%$ & 77 \\
\hline Discharge with $\mathrm{ttt}$ & 12 & $33 \%$ & 20 & $35 \%$ & 6 & $30 \%$ & 13 & $36 \%$ & 50 \\
\hline Dead & 6 & $17 \%$ & 8 & $13 \%$ & 3 & $15 \%$ & 5 & $14 \%$ & 23 \\
\hline Total & 36 & $100 \%$ & 58 & $100 \%$ & 20 & $100 \%$ & 36 & $100 \%$ & 150 \\
\hline
\end{tabular}

Chi-Square Tests: $\chi^{2}=0.111, \mathrm{df}=4, \mathrm{p}=0.999$.

Table 18. Correlation between way of delivery and the outcome.

\begin{tabular}{cccccc}
\hline \multirow{2}{*}{ Outcome } & \multicolumn{4}{c}{ Way of delivery } & \multirow{2}{*}{ Total } \\
\cline { 2 - 5 } & \multicolumn{2}{c}{ Vaginal delivery } & \multicolumn{2}{c}{ C/S } & \\
\cline { 2 - 5 } & No. & $\%$ & No. & $\%$ & \\
\cline { 2 - 5 } Discharge without ttt & 52 & $51 \%$ & 25 & $51 \%$ & 77 \\
Discharge with ttt & 33 & $33 \%$ & 17 & $35 \%$ & 50 \\
Died & 16 & $16 \%$ & 7 & $14 \%$ & 23 \\
Total & 101 & $100 \%$ & 49 & $100 \%$ & 150 \\
\hline
\end{tabular}

Chi-Square Tests: $\chi^{2}=0.094, \mathrm{df}=2, \mathrm{p}=0.954$.

Table 19. Correlation between main causes and the outcome.

\begin{tabular}{|c|c|c|c|c|c|c|c|c|c|c|c|}
\hline \multirow[b]{2}{*}{ Outcome } & \multicolumn{10}{|c|}{ Main causes of convulsions } & \multirow[b]{2}{*}{ Total } \\
\hline & 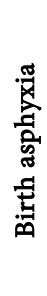 & 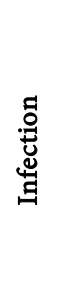 & 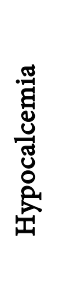 &  &  & 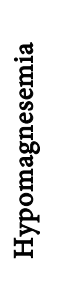 & 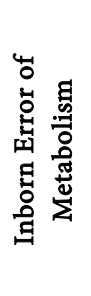 & 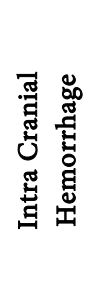 & 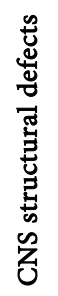 & 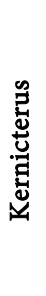 & \\
\hline Discharge without $\mathrm{ttt}$ & 19 & 15 & 17 & 8 & 10 & 3 & 1 & 0 & 2 & 2 & 77 \\
\hline Discharge with $\mathrm{ttt}$ & 21 & 8 & 4 & 4 & 2 & 0 & 4 & 2 & 4 & 1 & 50 \\
\hline Died & 5 & 1 & 0 & 0 & 0 & 0 & 10 & 3 & 3 & 1 & 23 \\
\hline Total & 45 & 24 & 21 & 12 & 12 & 3 & 15 & 5 & 9 & 4 & 150 \\
\hline
\end{tabular}

Chi-Square Tests: $\chi^{2}=39.753, \mathrm{df}=20, \mathrm{p}=0.005$.

\subsection{Analysis of Death}

Out of 150 babies 23 (15\%) babies were died:

- The major cause of death was inborn error of metabolism 10/23 (44\%), followed by birth asphyxia 5/23 (22\%) babies. 
Table 20. Distribution of babies according to causes of deaths $(n=23)$.

\begin{tabular}{ccc}
\hline Causes of deaths & No. & $\%$ \\
\hline Inborn error of metabolism & 10 & $44 \%$ \\
Birth asphyxia & 5 & $22 \%$ \\
Intra cranial hemorrhage & 3 & $13 \%$ \\
CNS structural defects & 3 & $13 \%$ \\
Infection & 1 & $4 \%$ \\
Kernicterus & 1 & $4 \%$ \\
Total & 23 & $100 \%$ \\
\hline
\end{tabular}

- Among babies with CNS structural defects three (13\%) died; two edwards and one patau syndrome.

- While one baby died from kernicterus as well as one from infection. As shown in Table 20.

\section{Conclusions}

- The majority of neonates who developed seizures were male and full term.

- The most common etiology of seizures is birth asphyxia.

- Hypocalcemia is most common biochemical abnormality.

- Subtle represents the commonest type of seizure.

- Phenobarbitone is still the most commonly prescribed anticonvulsant.

- Inborn error of metabolism carries a higher mortality rate.

- Statically analysis showed there is significant association between main causes of neonatal convulsions and the outcome with $\mathrm{p}=0.005$.

\section{Recommendations}

Regular updating of the data is recommended with increasing attention to save the data electronically. Improvement of antenatal services and obstetrical care with regular monitoring of fetal heart rate to ensure safe delivery and appropriate neonatal resuscitation to avoid birth asphyxia; Improvement of the laboratory services and the availability of investigations and other advanced procedures to detect and diagnose an inborn error of metabolism. EEG services are strongly needed in the unit. Quick assessment, timely diagnosis and aggressive management according to the etiology are necessary to prevent the morbidity and mortality associated with neonatal seizures. Future studies should include large sample size and should include other hospitals in our locality; in addition we recommend prospective studies which focus on the long term neurological and developmental outcome following neonatal seizures.

\section{Conflicts of Interest}

The authors declare no conflicts of interest regarding the publication of this paper. 


\section{References}

[1] Singh, M. (2010) Neurological Disorders. In: Textbook of Care of Newborn, Sagar Publication, New Delhi, 340-344.

[2] Mikati, M.A., Kliegman, R.M., Behrman, R.E. and Stanton, B.F. (2011) Seizures in Childhood. WB Saunders, Philadelphia, 2013-2037.

[3] Younkin, D.P., Delivoria-Papdopoulos, M., Maris, J., Donlon, E., Clancy, R. and Chance, B. (1986) Cerebral Metabolic Effects of Neonatal Seizures Measured with in Vivo ${ }^{31}$ P NMR Spectroscopy. Annals of Neurology, 20, 513-519. https://doi.org/10.1002/ana.410200412

[4] Najeeb, S., Qureshi, A.M., Rehman, A., Ahmad, F., Shah, S., Khan, A.Y., et al. (2012) Etiology and Types of Neonatal Seizures Presenting at Ayub Teaching Hospital Abbottabad. Journal of Ayub Medical College Abbottabad, 24, 33-37.

[5] Mizrah, E.M. (2001) Neonatal Seizures and Neonatal Epileptic Syndrome. Neurologic Clinics, 19, 427-463. https://doi.org/10.1016/S0733-8619(05)70025-6

\section{Abbreviations}

$\begin{array}{ll}\text { ABG } & \text { Arterial blood gas } \\ \text { AED } & \text { Antiepileptic drug } \\ \text { CNS } & \text { Central nervous system } \\ \text { C/S } & \text { Cesarean section } \\ \text { CSF } & \text { Cerebrospinal fluid } \\ \text { CT } & \text { Computed tomography } \\ \text { EEG } & \text { Electroencephalography } \\ \text { GABA } & \text { Gamma amino-butyric acid } \\ \text { HIE } & \text { Hypoxic-ischemic encephalopath } \\ \text { IEM } & \text { Inborn error of metabolism } \\ \text { ICH } & \text { Intra cranial hemorrhage } \\ \text { IM } & \text { Intramuscular } \\ \text { IV } & \text { Intravenous } \\ \text { LBW } & \text { Low birth weight } \\ \text { MRI } & \text { Magnetic resonance imaging } \\ \text { MSUD } & \text { Maple syrup urine disease } \\ \text { NICU } & \text { Neonatal intensive care unit } \\ \text { NNW } & \text { Neonatal ward } \\ \text { NS } & \text { Neonatal seizures } \\ \text { UTI } & \text { Urinary tract infectio } \\ \text { US } & \text { Ultrasound } \\ \text { TTN } & \text { Transient tachypnea of newborn } \\ \text { ttt } & \text { Treatment } \\ & \end{array}$

